\title{
Crystalline $\mathrm{Mg}_{2} \mathrm{SiO}_{4}$ and amorphous $\mathrm{Mg}$-bearing silicate grain formation by coalescence and growth
}

\author{
K. Kamitsuji ${ }^{1}$, H. Suzuki ${ }^{1}$, Y. Kimura ${ }^{2}$, T. Sato ${ }^{1}$, Y. Saito ${ }^{3}$, and C. Kaito ${ }^{1}$ \\ 1 Department of Nanophysics in Frontier Projects, Ritsumeikan University, Kusatsu-shi, Shiga 525-8577, Japan \\ e-mail: rp007988@se.ritsumei.ac.jp \\ 2 Laboratory for Extraterrestrial Physics, Code 691, NASA Goddard Space Flight Center, Greenbelt, MD 20771, USA \\ 3 Department of Electronics and Information Science, Kyoto Institute of Technology, Matsugasaki, Sakyo-ku, Kyoto 606-8585, \\ Japan
}

Received 28 May 2004 / Accepted 23 August 2004

\begin{abstract}
A novel method for producing $\mathrm{MgO}$ and $\mathrm{SiO}_{2}$ smokes was developed. Mg-bearing silicate grain formation using the coalescence and growth of $\mathrm{MgO}$ and $\mathrm{SiO}_{2}$ grains was carried out in our laboratory. It becomes evident that single and poly crystalline $\mathrm{Mg}_{2} \mathrm{SiO}_{4}$ (forsterite) and amorphous $\mathrm{Mg}$-bearing silicate grains can be produced by the coalescence and growth of $\mathrm{MgO}$ and $\mathrm{SiO}_{2}$ grains. This result suggests that the observed crystalline $\mathrm{Mg}_{2} \mathrm{SiO}_{4}$ grains and amorphous $\mathrm{Mg}$-bearing silicate particles in Red Super Giant (RSG), Asymptotic Giant Branch (AGB), post-AGB and planetary nebula (PNe) could be produced by the coalescence and growth of $\mathrm{MgO}$ and $\mathrm{SiO}_{2}$ grains.
\end{abstract}

Key words. astrochemistry - methods: laboratory - stars: AGB and post-AGB - circumstellar matter - dust, extinction

\section{Introduction}

IR spectra taken by the Infrared Space Observation (ISO) project of Red Super Giant (RSG), Asymptotic Giant Branch (AGB) stars, post-AGB stars and planetary nebula (PNe) indicated a mixture of amorphous and crystalline silicates (Waelkens et al. 1996; Waters et al. 1996). The observation of crystalline phases changed our view of the silicates. Although Mg-rich crystalline silicates were observed, Fe-rich crystalline silicates were not observed. The direct formation of $\mathrm{Mg}$-bearing crystalline silicates i.e., $\mathrm{Mg}_{2} \mathrm{SiO}_{4}$ (forsterite) and $\mathrm{MgSiO}_{3}$ (enstatite) grains was not achieved in condensation experiments in the laboratory (Nuth et al. 1988; Suzuki et al. 2000). On the other hand, experiments based on gas-solid direct condensation from $\mathrm{Mg}-\mathrm{Fe}-\mathrm{SiO}-\mathrm{H}_{2}-\mathrm{O}_{2}$ vapor yield various metastable phases (Rietmeijer et al. 1999).

In a previous paper, we demonstrated crystalline $\mathrm{Mg}_{2} \mathrm{SiO}_{4}$ grain formation due to the coalescence and growth of $\mathrm{Mg}$ and $\mathrm{SiO}$ smoke grains ( $\mathrm{Mg}-\mathrm{SiO}$ system) in the case of an $\mathrm{SiO}$-grain-rich atmosphere in a $\mathrm{Mg}$-SiO system (Kaito et al. 2003). These $\mathrm{Mg}_{2} \mathrm{SiO}_{4}$ grains contained silicon crystallites. This was the first time that crystalline $\mathrm{Mg}_{2} \mathrm{SiO}_{4}$ grain formation had been achieved in the laboratory by coalescence and growth.

In spite of increasing interest in the formation of refractory compound particles in materials science and astrophysics (Henning et al. 2002; Colangeli et al. 2003), the unavailability of a suitable evaporation source for the reaction gas

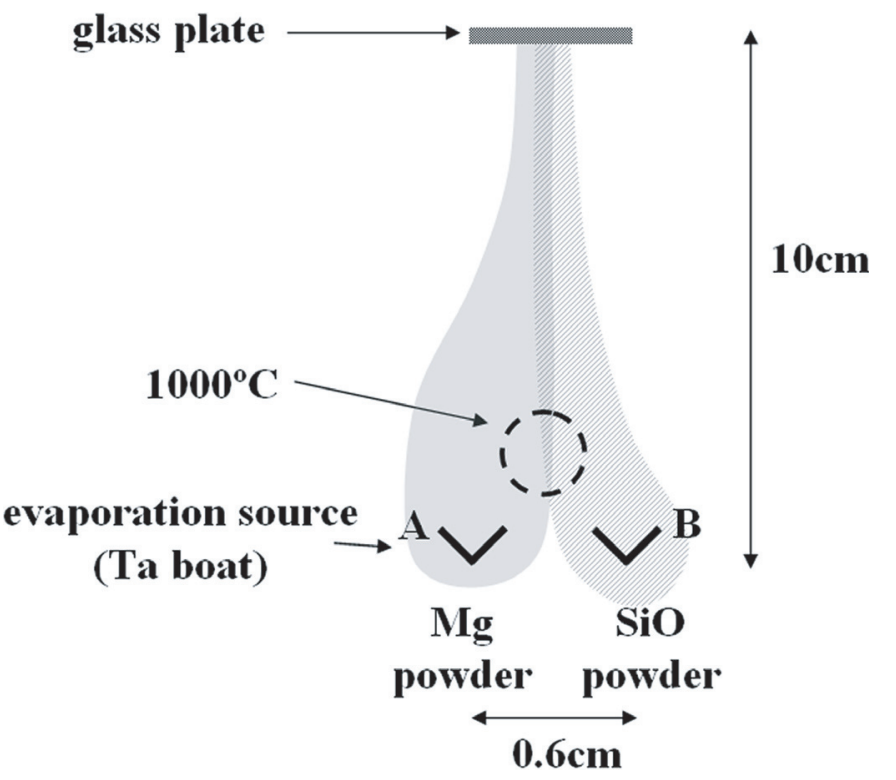

Fig. 1. Schematic representation of the production of compound grains by mixing two smokes. Boat $\mathrm{A}$ is a $\mathrm{Mg}$ evaporation source. Boat $\mathrm{B}$ is a $\mathrm{SiO}$ evaporation source. In the gas mixture of $\mathrm{Ar}$ and $\mathrm{O}_{2}$, boats $\mathrm{A}$ and B were heated to 800 and $1400{ }^{\circ} \mathrm{C}$, respectively. An outline of the two smoke cloud shapes is presented.

remains an unavoidable problem. We recently found that some oxide grains can be produced by the use of a tantalum (Ta) boat in a gas mixture (Atou et al. 2003). In the present grain 


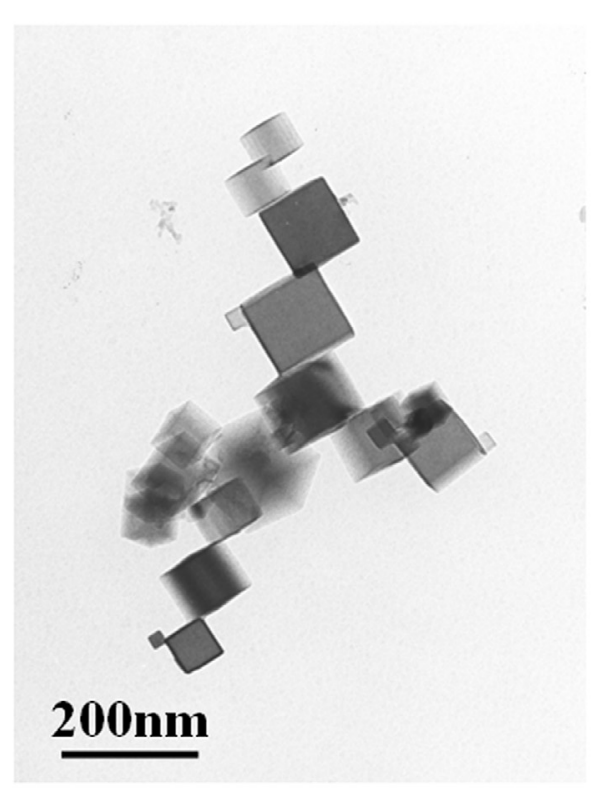

MgO grains

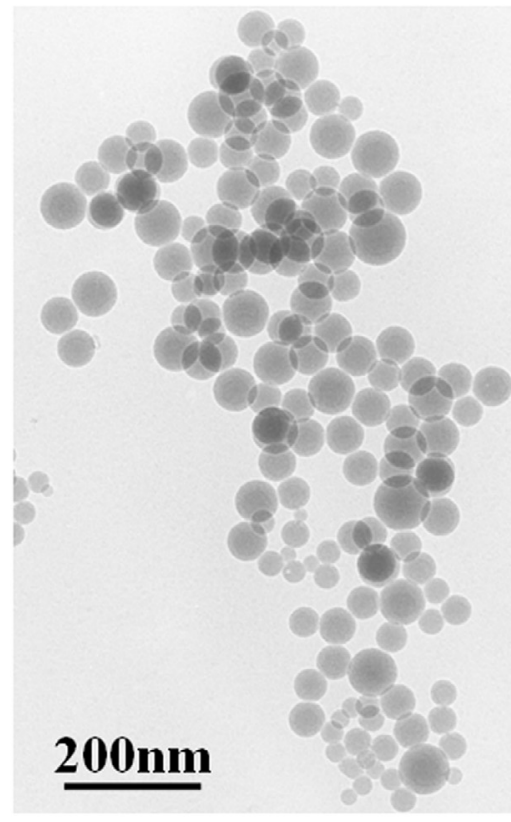

$\mathrm{SiO}_{2}$ grains

Fig. 2. Typical smoke grains of crystalline $\mathrm{MgO}$ and amorphous $\mathrm{SiO}_{2}$ collected under the present experimental conditions.

formation experiments, we adapted this technique, and the coalescence of $\mathrm{MgO}$ and $\mathrm{SiO}_{2}$ smoke grains $\left(\mathrm{MgO}-\mathrm{SiO}_{2}\right.$ system) was successfully carried out. Spherical crystalline $\mathrm{Mg}_{2} \mathrm{SiO}_{4}$ grains without silicon crystallites, and amorphous $\mathrm{Mg}$-bearing silicate grains, can be obtained on the basis of the coalescence between $\mathrm{MgO}$ and $\mathrm{SiO}_{2}$ grains. In the present case, the crystalline $\mathrm{Mg}_{2} \mathrm{SiO}_{4}$ grains formed were both single crystals and polycrystalline.

\section{Experimental}

The evaporation chamber was a glass cylinder of $17 \mathrm{~cm}$ diameter and $30 \mathrm{~cm}$ height, covered with stainless steel on top and connected to a high-vacuum exhaust through a valve at its bottom. After evacuation of the chamber, smoke was produced by introducing a gas mixture of $\mathrm{O}_{2}$ gas at 20 Torr and $\mathrm{Ar}$ gas at 80 Torr. In the present experiment, two evaporation sources in V-shaped tantalum boats $(50 \mathrm{~mm}$ long, $2 \mathrm{~mm}$ wide and $1 \mathrm{~mm}$ deep) were set as shown schematically in Fig. 1. Boats A and $\mathrm{B}$ were charged with $\mathrm{Mg}$ and $\mathrm{SiO}$ powder, respectively. By heating boats $\mathrm{A}$ and $\mathrm{B}$ to 800 and $1400{ }^{\circ} \mathrm{C}$, respectively, in the gas mixture, $\mathrm{MgO}$ and $\mathrm{SiO}_{2}$ smokes were produced and mixed as indicated in a previous paper on the $\mathrm{Mg}-\mathrm{SiO}$ system (Kaito et al. 2003). The smoke grains in the mixed region were collected at a height of $10 \mathrm{~cm}$ above the evaporation source. The collected samples were observed using Hitachi H-7100R and H-9000NAR transmission electron microscopes (TEM). The composition of the grains was determined using an energy-dispersive X-ray (EDX) spectrometer (Horiba EMAX-5370) attached to the H-7100R electron microscope. The transmission IR spectra of the collected samples, embedded in $\mathrm{KBr}$ pellets, were measured with a Fourier transform

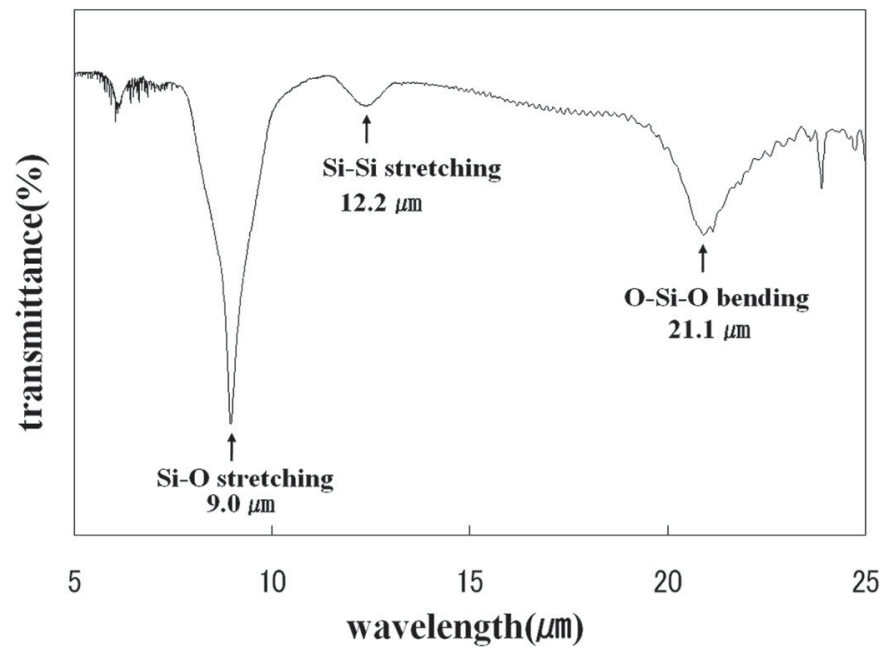

Fig. 3. IR spectrum of the $\mathrm{SiO}_{2}$ grains produced in our experiment. The spectrum for quartz can be seen.

infrared spectrometer (FTIR, Horiba FT210) in the wavelength region from 2.5 to $25 \mu \mathrm{m}$ (4000 to $400 \mathrm{~cm}^{-1}$ ).

\section{Results and discussion}

Typical $\mathrm{MgO}$ and $\mathrm{SiO}_{2}$ grains produced in a gas mixture of $\mathrm{Ar}$ and $\mathrm{O}_{2}$ are shown in Fig. 2. As is well known, cubic $\mathrm{MgO}$ grains are produced by the oxidation of $\mathrm{Mg}$ vapor. Spherical amorphous $\mathrm{SiO}_{2}$ grains were obtained by evaporating $\mathrm{SiO}$ powder in the mixture of $\mathrm{O}_{2}$ and $\mathrm{Ar}$ (Kaito et al. 1987). The IR spectrum of the $\mathrm{SiO}_{2}$ grains is shown in Fig. 3. The IR spectrum can be identified as quartz (Morioka et al. 1998). By evaporating $\mathrm{SiO}$ grains in the gas mixture containing $\mathrm{O}_{2}$, $\mathrm{SiO}$ grains were changed to $\mathrm{SiO}_{2}$ by oxidation. The grains were 


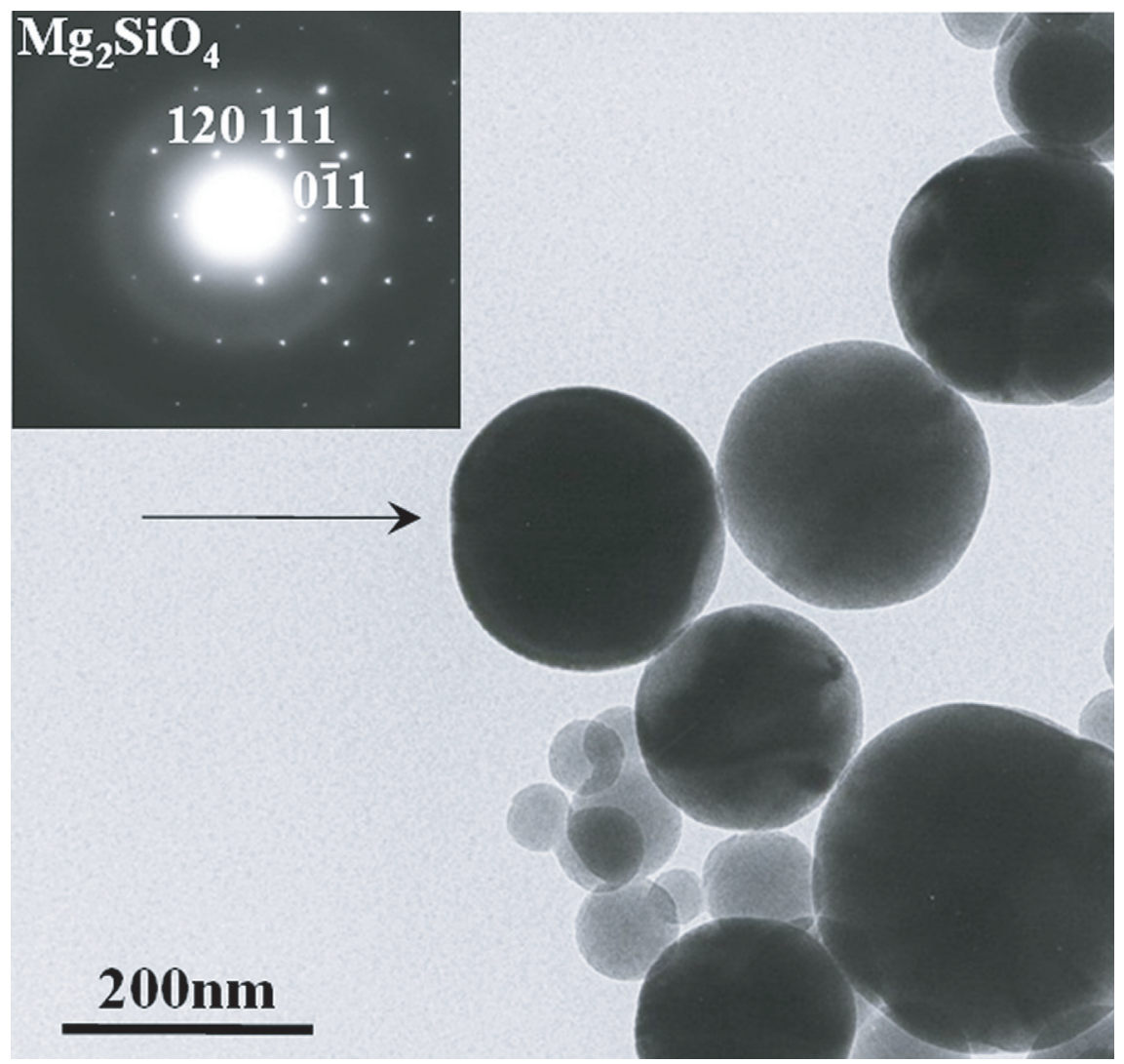

Fig. 4. The grain indicated by an arrow is a single crystal $\mathrm{Mg}_{2} \mathrm{SiO}_{4}$ grain.
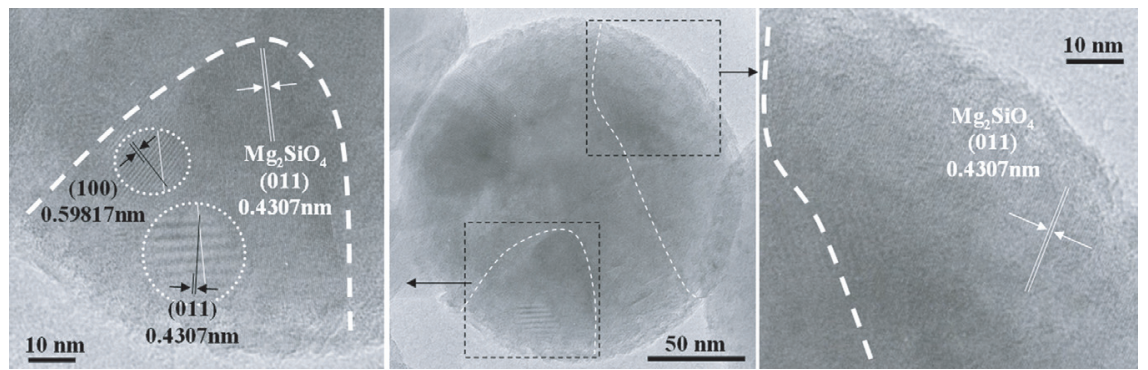

Fig. 5. HREM image of a polycrystalline $\mathrm{Mg}_{2} \mathrm{SiO}_{4}$ grain. Dotted lines show the boundary seen in the grain. Moire fringes are also seen in the left enlarged image.

spherical, and the $\mathrm{O}-\mathrm{Si}-\mathrm{O}$ bending peak at $21.1 \mu \mathrm{m}$ is sharper than in other silicate grains.

As was observed in the $\mathrm{Mg}-\mathrm{SiO}$ system, the $\mathrm{Mg}_{2} \mathrm{SiO}_{4}$ grains were obtained in the mixed smoke region of the $\mathrm{MgO}-\mathrm{SiO}_{2}$ system. In the case of the $\mathrm{MgO}$-rich side of the smoke, $\mathrm{MgO}$ crystals appeared shaped as truncated cubic grains. In the case of the $\mathrm{SiO}_{2}$-rich side, spherical amorphous $\mathrm{SiO}_{2}$ grains were obtained.

As shown in Fig. 4, spherical grains with strong contrasts are seen, and these contrasts suggest the formation of crystalline grains. The selected area electron diffraction (ED) pattern of the grain, indicated by an arrow, is shown in the inset in the figure. The ED pattern shows the formation of a single $\mathrm{Mg}_{2} \mathrm{SiO}_{4}$ crystal.

Figure 5 shows a high-resolution electron microscope (HREM) image of the $\mathrm{Mg}_{2} \mathrm{SiO}_{4}$ grain. This grain was composed of polycrystalline grains. Enlarged images of the regions in the dotted squares are also shown. The lattice image of the (011) plane of $\mathrm{Mg}_{2} \mathrm{SiO}_{4}$ is seen in both enlarged images, but these images are not parallel, that is, polycrystalline growth occurred. The dotted lines indicate the boundaries seen in the grain. Since some parts of the $\mathrm{Mg}_{2} \mathrm{SiO}_{4}$ crystals in a grain overlap at the boundary, Moire fringes are also seen.

In addition to the above-mentioned single crystal and polycrystalline $\mathrm{Mg}_{2} \mathrm{SiO}_{4}$ grains, spherical amorphous grains were produced as shown in Fig. 6 by their halo ED pattern. By means of EDX analysis, the existence of $\mathrm{Mg}$ and $\mathrm{Si}$ atoms in the spherical grains has been confirmed. The spherical grains indicated in Fig. 2 show the existence of silicon atoms alone. Therefore, it can be concluded that the spherical amorphous Mg-bearing silicate grains were also produced in the present experiment.

In the present experiment with oxygen gas, the oxidation of $\mathrm{Mg}$ vapor occurred near the heat source. The temperature of the mixed smoke in the $\mathrm{MgO}-\mathrm{SiO}_{2}$ system reached 


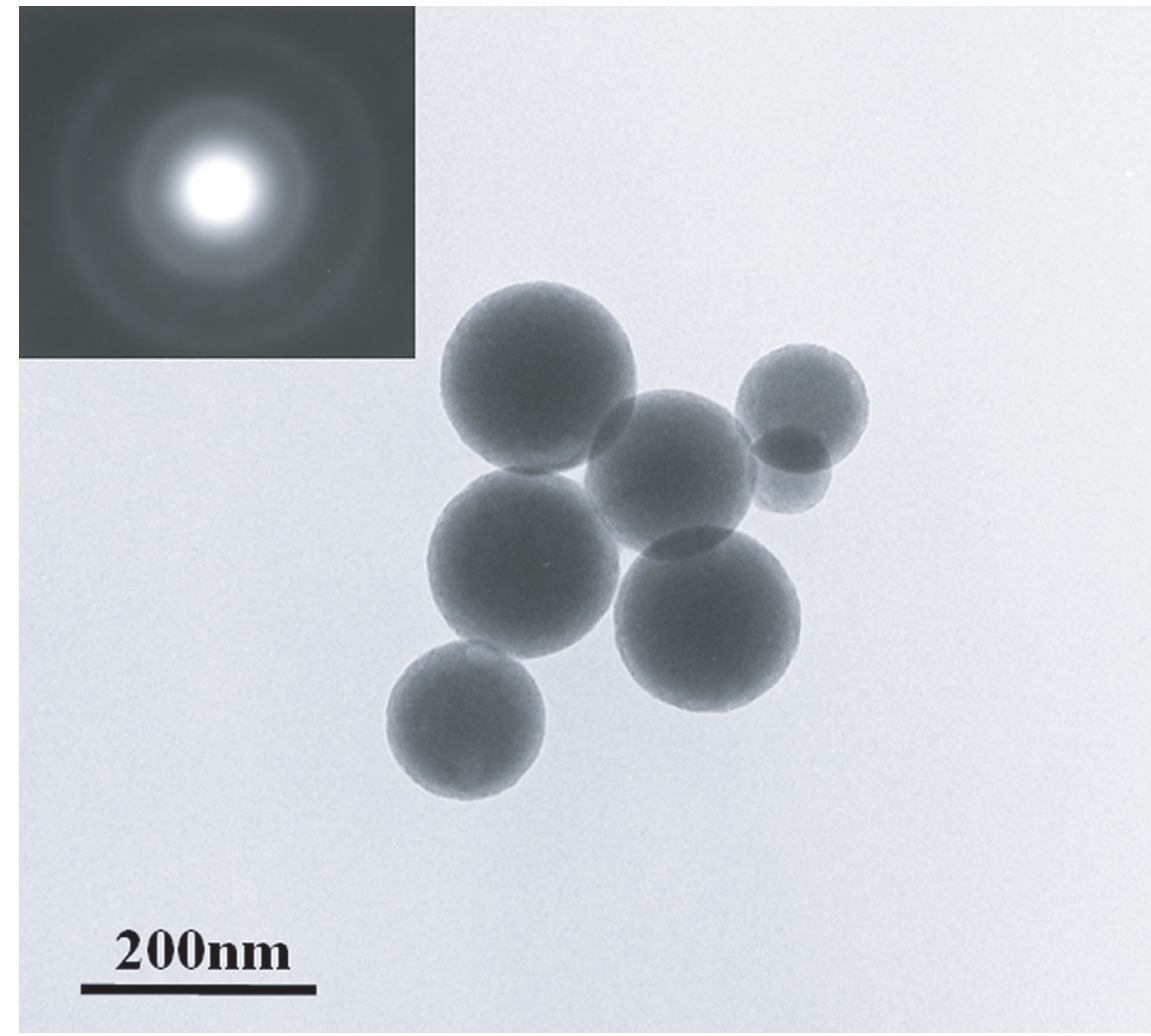

Fig. 6. Mg-bearing amorphous silicate grains. The ED pattern for these spherical grains shows a halo.

approximately $1000{ }^{\circ} \mathrm{C}$ (Kaito \& Shiojiri 1982; Kaito 1984; Kaito \& Fujita 1986). The cooling rate of the smoke is of the order of $10^{-3}-10^{-4} \mathrm{~K} / \mathrm{s}$. The difference in cooling rate in the smoke after the coalescence of $\mathrm{MgO}$ and $\mathrm{SiO}_{2}$ grains may determine whether single crystal, poly crystal or amorphous grains are formed. It is concluded that $\mathrm{Mg}_{2} \mathrm{SiO}_{4}$ crystals can be produced by the coalescence of $\mathrm{MgO}$ and $\mathrm{SiO}_{2}$ grains, e.g. the direct collision of $\mathrm{MgO}$ and $\mathrm{SiO}_{2}$ grains.

With respect to the production process of crystalline $\mathrm{Mg}_{2} \mathrm{SiO}_{4}$ and amorphous $\mathrm{Mg}$-bearing silicate grains, it is found that these grains have the same spherical shape. The amorphous grains were generally of spherical shape. In the present experiment, crystalline $\mathrm{Mg}_{2} \mathrm{SiO}_{4}$ grains did not have the characteristic crystalline shape (Uyeda 1987), and were instead spherical grains with no obvious faces. This suggests that amorphous Mg-bearing silicate grains were produced first and subsequently the crystallization of amorphous $\mathrm{Mg}$-bearing silicate to $\mathrm{Mg}_{2} \mathrm{SiO}_{4}$ occurred due to thermal annealing. The crystallization process for a $\mathrm{Mg}$-bearing silicate by in situ observation techniques using a TEM will be shown elsewhere.

\section{Conclusions}

Crystalline $\mathrm{Mg}_{2} \mathrm{SiO}_{4}$ grains and amorphous $\mathrm{Mg}$-bearing silicate particles can be produced by the coalescence and growth of $\mathrm{MgO}$ and $\mathrm{SiO}_{2}$ grains. The structural differences between crystalline and amorphous grains may have occurred due to differences in cooling rate after the formation of the amorphous $\mathrm{Mg}$-bearing silicate grains in the mixed smoke. The crystalline $\mathrm{Mg}_{2} \mathrm{SiO}_{4}$ grains and amorphous $\mathrm{Mg}$-bearing silicate particles observed in RSG, AGB, post-AGB and PNe (Waelkens et al. 1996; Waters et al. 1996) may therefore have been produced by the coalescence and growth of $\mathrm{MgO}$ and $\mathrm{SiO}_{2}$ grains or $\mathrm{Mg}$ and $\mathrm{SiO}$ grains (Kaito et al. 2003).

\section{References}

Atou, Y., Suzuki, H., Kimura, Y., et al. 2003, Physica E, 16, 179 Colangeli, L., Henning, Th., et al. 2003, A\&ARv, 11, 97

Henning, Th., et al. 2002, Astromineralogy, ed. Th. Henning (Berlin: Springer)

Kaito, C., \& Shiojiri, M. 1982, Jpn J. Appl. Phys., 21, L421

Kaito, C. 1984, Jpn J. Appl. Phys., 23, 525

Kaito, C., \& Fujita, K. 1986, Sci. Form, 2(1), 37

Kaito, C., Shoji, R., \& Fujita, K. 1987, Jpn J. Appl. Phys., 26, L965

Kaito, C., Ojima, Y., Kamitsuji, K., et al. 2003, Meteoritics Planet. Sci., 38, 49

Morioka, T., Kimura, S., Tsuda, N., et al. 1998, MNRAS, 299, 78

NuthIII, J. A., Nelson, R. N., Moore, M., \& Donn, B. 1988, in Experiments on Cosmic Dust Analogues, ed. E. Bussoletti, C. Fusco, \& G. Longo (Dordrecht: Kluwer), 191

Rietmeijer, F. J. M., NuthIII, J. A., \& Karner, J. M. 1999, ApJ, 527, 395

Suzuki, N., Kimura, S., Nakada, T., et al. 2000, Meteoritics Planet. Sci., 35, 1269

Uyeda, R. 1987, in Morphology of Crystal, part B, ed. I. Sunagawa (Tokyo: Terra)

Waelkens, C., Waters, L. B. F. M., de Graauw, M. S., et al. 1996, A\&A, $315, \mathrm{~L} 245$

Waters, L. B. F. M., Molster, F. J., de Jong, T., et al. 1996, A\&A, 315, L361 